\title{
Relação entre as variáveis morfométricas extraídas de dados SRTM (Shuttle Radar Topography Mission) e a vegetação do Parque Nacional de Brasília
}

\author{
Polyanna da Conceição Bispo ${ }^{1,2}$, Márcio de Morisson Valeriano ${ }^{1}$ e Tatiana Mora Kuplich ${ }^{1}$
}

Recebido em 8/7/2008. Aceito em 7/5/2009

\begin{abstract}
RESUMO - (Relação entre as variáveis morfométricas extraídas de dados SRTM (Shuttle Radar Topography Mission) e a vegetação do Parque Nacional de Brasília). Este trabalho visa ao estudo da relação entre a distribuição de fitofisionomias do Parque Nacional de Brasília (PNB) e variáveis topográficas, para avaliar o potencial de dados SRTM isoladamente, como complemento aos dados tradicionalmente aplicados no sensoriamento remoto da vegetação. Esta relação foi verificada através de análises discriminantes entre o mapa de vegetação referência do PNB e as seguintes variáveis morfométricas: elevação, declividade, orientação de vertente, curvatura vertical e curvatura horizontal. Tais análises indicaram as classes de vegetação que podem ser separadas com base nas condições topográficas do terreno. As variáveis morfométricas mais importantes na distinção entre os tipos vegetacionais foram a elevação, a declividade e a orientação de vertente. Apesar de os dados morfométricos mostrarem potencial indicativo das classes de vegetação, as análises resultaram em discriminação em um nível aquém do detalhamento temático do mapa referência. Tal desempenho pode ser explicado pela incompatibilidade das escalas de variação exibidas entre os dados morfométricos em relação ao tamanho das unidades de mapeamento da vegetação. Além disso, a variação de tipos de vegetação do cerrado pode ser explicada por uma série de outros fatores além da topografia. Com base nas análises discriminantes das variáveis morfométricas, foi possível o mapeamento experimental da vegetação ao nível de subfisionomias.
\end{abstract}

Palavras-chave: topografia, vegetação, Cerrado, SRTM, Parque Nacional de Brasília

ABSTRACT - (Relationship between morphometric variables extracted from SRTM (Shuttle Radar Topography Mission) data and vegetation in Brasília National Park ). This paper aims to study the relationship between the distribution of vegetation in Brasilia National Park and topographic variables, to evaluate the potential of SRTM data alone, in addition to data traditionally used in remote sensing of vegetation. A map of vegetation of the area was used as a reference and the morphometric variables (elevation, slope, aspect and profile and plane curvatures) were compared to the mapped units. Analyses indicated vegetation types easily discriminated depending on topographic position. The variables elevation, slope and aspect were shown to be the most important for their high discrimination power of the vegetation types. Although morphometric data are recognized as having strong potential for characterizing vegetation, this was not shown in the results, due to the mismatching of variability scales between the two sources of data, where large units tend to exhibit similar distribution patterns of morphometry, and comprise classes with different responses for morphometric constraints. Discriminant analyses of morphometric variables allowed vegetation mapping up to sub-physiognomy levels.

Key words: topography, vegetation, Brazilian Cerrado, SRTM, Brasilia National Park

\section{Introdução}

O Cerrado, segundo maior bioma brasileiro, é constituído por uma alta diversidade de espécies vegetais e de fitofisionomias. Estas se apresentam como um mosaico de formas fisionômicas abrangendo desde as formas campestres, como campo limpo, até as florestais como o cerradão, passando por formas intermediárias como o campo sujo, campo cerrado e cerrado stricto sensu (Coutinho 1978; Castro et al. 1999). Esta variação fitofisionomica é determinada pelo mosaico de manchas de solo mais ou menos pobres, pela irregularidade dos regimes hídricos, características de queimada de cada local (freqüência, época, intensidade) e ação humana. Alguns autores sugerem também que há uma relação entre as fitofisionomias e as variações topográficas (Oliveira \& Martins 1986; Furley \& Ratter 1988; Oliveira Filho et al. 1989; Furley 1996, Cardoso \& Schiavini 2002; Fonseca \& Silva Júnior 2004, Carvalho et al. 2005; Ruggiero et al. 2006), bem como a dinâmica da água no solo (Oliveira \& Martins 1986; Oliveira Filho et al. 1989; Oliveira Filho et al. 1997) que está diretamente ligada às condições topográficas do terreno. Entretanto, a maioria destes estudos apresenta resultados contraditórios, uma vez que relacionam variações fisiográficas às comunidades vegetais baseando-se apenas em coleta de dados pontuais. Desse modo torna-se interessante a utilização de informações especializadas, principalmente na forma de mapas, para se analisar as relações entre os elementos da paisagem (Ruggiero et al. 2006). Neste sentido, tais elementos, em especial a topografia, podem dar suporte ao mapeamento das fitofisionomias vegetais.

Embora se reconheçam os dados topográficos como importante fonte de informações para subsidiar o mapeamento da vegetação (Dargie 1984; Dargie 1987; Kirkby et al. 1990; Florinsky \& Kuryakova 1996; Velázquez-Rosas et al. 2002), o estabelecimento de metodologias com este aporte ainda requer o desenvolvimento de estudos específicos (Kellndorfer et al. 2004). Tal condição pode ser explicada por uma histórica ausência de levantamentos topográficos detalhados, pela qual grande parte do território nacional permanece com mapeamentos em escalas inadequadas para várias aplicações. Neste contexto, a utilização de bases topográficas obtidas por sensores orbitais pode significar a viabilização desses estudos.

A missão SRTM (Shuttle Radar Topography Mission), ocorrida em 2000, possibilitou a coleta de dados altimétricos para praticamente toda a superfície terrestre. A existência desses dados em cobertura nacional permite que se avalie e se desenvolva seu potencial para o mapeamento da vegetação de forma relativamente padronizada em diferentes

Instituto Nacional de Pesquisas Espaciais, São José dos Campos, SP, Brasil

Autor para correspondência: polyanna@1tid.inpe.br 
ambientes. Os dados SRTM são passíveis de derivação em variáveis morfométricas (ou, na denominação mais recente, geomorfométricas) para expressão das diferentes características do relevo, o que resulta num conjunto de dados em complemento à altimetria (Valeriano 2005).

Cada variável condiciona a vegetação através de diferentes aspectos da paisagem (temperatura, exposição solar e hidrologia, por exemplo), além de exercer controle direto sobre o transporte e o acúmulo de nutrientes, estruturas de propagação, biomassa e substâncias vegetais, que afetam sua distribuição. A variável elevação corresponde à altitude do terreno está relacionada à distribuição altitudinal do solo e clima, condicionando diferentes padrões vegetacionais na paisagem. A declividade por sua vez possui ação direta sobre o equilíbrio entre a infiltração de água no solo e escoamento superficial, além de controlar a intensidade dos fluxos de matéria e insolação (Schmidt et al. 2003). Esse conjunto de fatores resulta na formação de ambientes com diferentes características físicas e biológicas, as quais permitem o estabelecimento de diferentes tipos de vegetação. A orientação de vertentes corresponde ao alinhamento do terreno em relação ao Sol, é a medida do ângulo horizontal da direção esperada do escoamento superficial, geralmente expressa em azimute. Dentre os vários aspectos (relação com distribuição de diferentes substratos, refúgios ecológicos etc.), esta variável relaciona-se ao grau de sombreamento ou iluminação do terreno selecionando ambientes mais propícios para o desenvolvimento de determinados tipos de vegetação em detrimento de outros. Assim, a orientação de vertentes controla a direção dos fluxos de matéria e insolação, portanto, com efeitos locais sobre os regimes hídricos e de energia, definindo diferentes padrões vegetacionais. A curvatura vertical refere-se ao caráter convexo/côncavo do terreno quando analisado em perfil, enquanto a curvatura horizontal refere-se ao caráter divergente/convergente das linhas de fluxos em projeção horizontal. Estas duas últimas variáveis combinadas representam uma caracterização das formas do terreno, influenciando os processos de migração e acúmulo de água, minerais e matéria orgânica no solo através da superfície, proporcionados pela gravidade (Schmidt et al. 2003).

Este trabalho visa ao estudo da relação entre a distribuição de fitofisionomias e variáveis topográficas, para avaliar o potencial de dados SRTM isoladamente, como complemento aos dados tradicionalmente aplicados no sensoriamento remoto da vegetação. Neste objetivo, o estudo buscou selecionar as variáveis morfométricas que melhor caracterizam os tipos de vegetação do Parque Nacional de Brasília e, reciprocamente, identificar as condições morfométricas para ocorrência das diferentes classes observadas.

\section{Material e métodos}

Área de estudo - Como representante do bioma Cerrado foi selecionada a área do Parque Nacional de Brasília (PNB), localizado entre as coordenadas $15^{\circ} 45^{\prime}-15^{\circ} 33^{\prime} \mathrm{S}$ e $48^{\circ} 06^{\prime}-47^{\circ} 50^{\prime} \mathrm{W}$. Esta área possui uma extensão aproximada de 30 mil hectares, sendo a unidade de conservação de maior destaque no Distrito Federal. Tal importância se deve à presença de inúmeras espécies representativas da fauna e flora do bioma Cerrado, assim como importantes mananciais hídricos.

Segundo a carta climática do Distrito Federal, a região do Parque Nacional de Brasília está submetida a dois tipos de clima, de acordo com a temperatura local (Köppen): o Cwa, tropical de altitude com temperatura do mês mais frio a $18^{\circ} \mathrm{C}$, e a média do mês mais quente superior a $22^{\circ} \mathrm{C}$ (cotas altimétricas de 1.000-1.200 m); e o $C w b$, tropical de altitude com temperatura do mês mais frio inferior a $18^{\circ} \mathrm{C}$, e média do mês mais quente inferior a $22{ }^{\circ} \mathrm{C}$ (cotas altimétricas acima de $1.200 \mathrm{~m}$ ). A ocorrência de chuvas se dá nos meses de outubro a março, com máxima de dezembro a agosto. Entre os meses de abril a setembro ocorre a época seca, sendo que os meses mais críticos são junho e julho (Ferreira 2003).

Os principais tipos de solos encontrados no PNB são os Latossolos Vermelho-Escuro e Vermelho-Amarelo (cerca de 38\%), os Cambissolos (cerca de 22\%) e os Solos Hidromórficos (Ramos 1995). Os demais grupos, como Podzólicos hidromórficos, aparecem em trechos isolados.

No Parque Nacional de Brasília estão reunidas as principais fitofisionomias do bioma Cerrado, subdivididas em três estratos vegetacionais, de acordo com a classificação definida por Ribeiro \& Walter (1998): campo limpo e campo sujo (estrato herbáceo arbustivo); campo cerrado e cerrado stricto sensu (estrato arborescente); e mata-galeria (estrato arbóreo). O cerradão, classe pertencente ao estrato arbóreo do Cerrado, não é encontrado no Parque. Porém, segundo Ferreira (2003) é possível, ainda, se distinguir nesse ambiente o campo limpo úmido, campo limpo com Murundum, campo úmido, campo cerrado com Trembléias, campo sujo com presença de Lychnophora ericoides (amica) e "canela de ema", mata de interflúvio e brejo (Fig. 1).

Dados cartográficos - O mapa de vegetação do Parque Nacional de Brasília utilizado foi o de Ferreira (2003), na escala 1:10.000, gerado a partir da atualização de um mapa de vegetação pré-existente. Esta atualização foi feita a partir da aplicação de um modelo linear de mistura espectral sobre uma cena do ETM $^{+} /$LANDSAT-7 e emprego de cenas IKONOS II de porções da parte leste e oeste da área (Ferreira 2003).

Os dados topográficos provieram do banco de dados morfométricos TOPODATA (Valeriano 2005), preparados conforme os procedimentos estabelecidos nesta iniciativa. Os dados SRTM das áreas selecionadas foram refinados de 3" para 1" com krigagem e em seguida derivados em variáveis morfométricas através de diferentes operações de vizinhança (Valeriano et al. 2006). Foram derivadas as seguintes variáveis: declividade $(G)$, orientação de vertentes $(A)$, curvatura vertical $\left(k_{v}\right)$ e curvatura horizontal $\left(k_{h}\right)$, além da própria elevação $(h)$, para área de estudo.

O mapa de vegetação foi publicado em projeção cartográfica UTM e datum horizontal SAD69 e os dados SRTM originais em projeção Geográfica e datum horizontal WGS84. A base de dados TOPODATA utilizada neste estudo, gerada a partir do SRTM, apresenta-se em projeção latlong e datum horizontal WGS84. Em Sistema de Informação Geográfica (SIG), os dados de vegetação foram convertidos para projeção latlong, com datum horizontal WGS84. Este passo foi feito através de operações de exportação e importação, em função das diferentes modalidades de conversão requeridas e das diferentes possibilidades de cada SIG usado. Após todo o trabalho de conversões, os dados foram definitivamente armazenados em Idrisi, onde foram realizadas as manipulações finais de preparo (geometria, resolução e posicionamento), assim como todo o processamento a partir de então. Desse modo, a estrutura definitiva de armazenamento dos dados da área de estudo foi: $48^{\circ} 6^{\prime} 37^{\prime \prime}\left(\mathrm{x}_{\text {mín }}\left({ }^{\circ}\right)\right), 15^{\circ} 45^{\prime} 5^{\prime \prime}\left(\mathrm{y}_{\text {mín }}\left({ }^{\circ}\right)\right), 47^{\circ} 50^{\prime} 26^{\prime \prime}\left(\mathrm{x}_{\text {máx }}\left({ }^{\circ}\right)\right)$, $15^{\circ} 33^{\prime} 24^{\prime \prime}\left(\mathrm{y}_{\text {máx }}\left({ }^{\circ}\right)\right), 971\left(\mathrm{n}^{\circ}{ }^{\circ}\right), 867\left(\mathrm{n}^{\circ}{ }^{\circ}\right)$, projeção latlong, datum WGS84

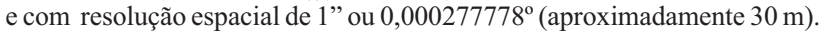

Amostragem e análise dos dados - Após a seleção do mapa de vegetação foi feita a migração e a compatibilização destes dados com os dados morfométricos. Foi feita uma amostragem das variáveis por classe vegetacional em esquema aleatório estratificado. Foram definidas diferentes densidades de amostragem para que em cada classe fossem escolhidos aproximadamente 50 pontos. Os dados amostrados foram pareados em planilhas de acordo com sua posição geográfica e o conteúdo destas planilhas submetido às análises estatísticas.

A separabilidade estatística das classes de vegetação com base nas variáveis morfométricas foi verificada através de análises discriminantes (Manly 1994). A aplicação das análises foi feita após agrupar classes de 
vegetação com estruturas semelhantes, que no mapa de referência estavam muito particularizadas. Estas análises foram aplicadas também dentro dos grupos vegetacionais formados por mais de duas subfisionomias, com o intuito de avaliar o uso das variáveis morfométricas como indicadores de classes no nível das subfisionomias vegetais. Para melhorar a linearidade dos dados, estes foram logaritmizados e posteriormente padronizados.

As novas classes de vegetação formadas a partir do reagrupamento dos dados de vegetação originais foram: (i) mata (mata-galeria, brejo e mata de interflúvio), (ii) campo cerrado (campo cerrado e campo cerrado com Trembléias), (iii) campo sujo (campo sujo e campo sujo com presença de Lychnophora ericoides (amica) e "canela de ema"), (iv) campo limpo (campo limpo, campo limpo úmido e campo limpo com Murundum) e (v) cerrado stricto senso.

As análises discriminantes aplicadas sobre as classes vegetacionais reagrupadas, assim como dentro dos grupos que incluíam mais de duas subfisionomias, indicaram as variáveis morfométricas de maior peso na separação dos grupos, bem como quais desses grupos melhor se separavam entre si. Os planos de informação das variáveis morfométricas foram operados com a equação da primeira função discriminante (na qual a maior parte da variação dos dados se concentrou), resultando em uma nova imagem, referente a esta função. Um mapa experimental de vegetação foi gerado a partir de classificações por fatiamentos aplicadas sobre essa imagem. Este fatiamento de níveis de intensidade consiste simplesmente em realçar os pixels cujas intensidades se situam dentro do intervalo especificado (a fatia), isto é, entre um máximo e um mínimo observado na imagem associando uma classe temática a cada intervalo de níveis. O mapa gerado foi editado em comparação com os dados de vegetação agrupados sob as novas classes, em função das similaridades observadas.

\section{Resultados e discussão}

Efeito do relevo sobre as fisionomias vegetais e sobre as suas subfisionomias - $\mathrm{Na}$ apreciação inicial dos dados topográficos (Fig. 2), verifica-se que a área específica do Parque corresponde a um tipo de terreno pouco movimentado entre os diversos compartimentos que ocorrem na região de seu entorno. Os mapas morfométricos exibem as faixas de amplitude numérica dos dados topográficos da área restrita do Parque, além da distribuição geográfica de cada variável. Da apreciação geral destes mapas, percebe-se que há um detalhamento dos dados de vegetação (Fig. 1) superior

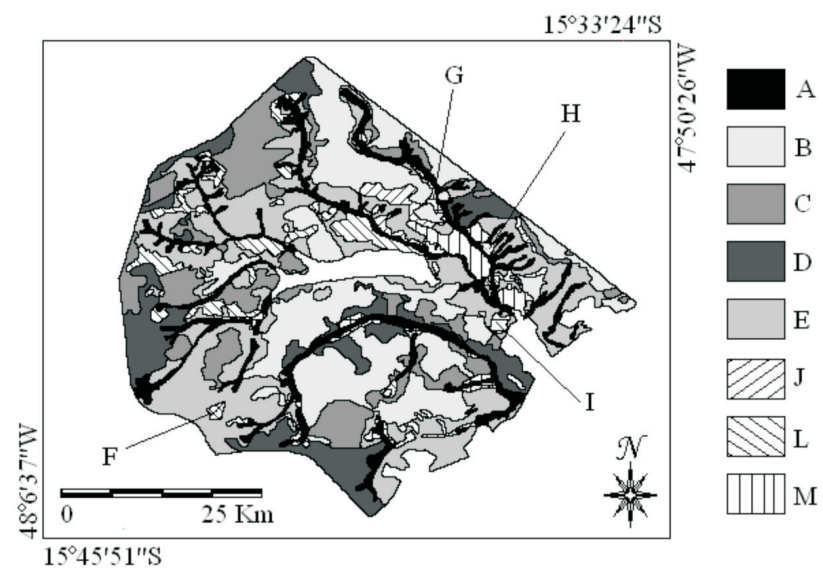

Figura 1. Mapa de vegetação com as classes A (mata-galeria), B (Cerrado stricto sensu), C (campo cerrado), D (campo sujo), E (campo limpo), F (campo limpo úmido), G (brejo), H (mata de interflúvio), I (reflorestamento), J (campo cerrado com Trembléias), L (campo limpo com Murundum) e M (campo sujo com presença de Lychnophora ericoides (amica) e "canela de ema". As classes F, G, H e I foram assinaladas porque apresentam apenas uma única mancha.
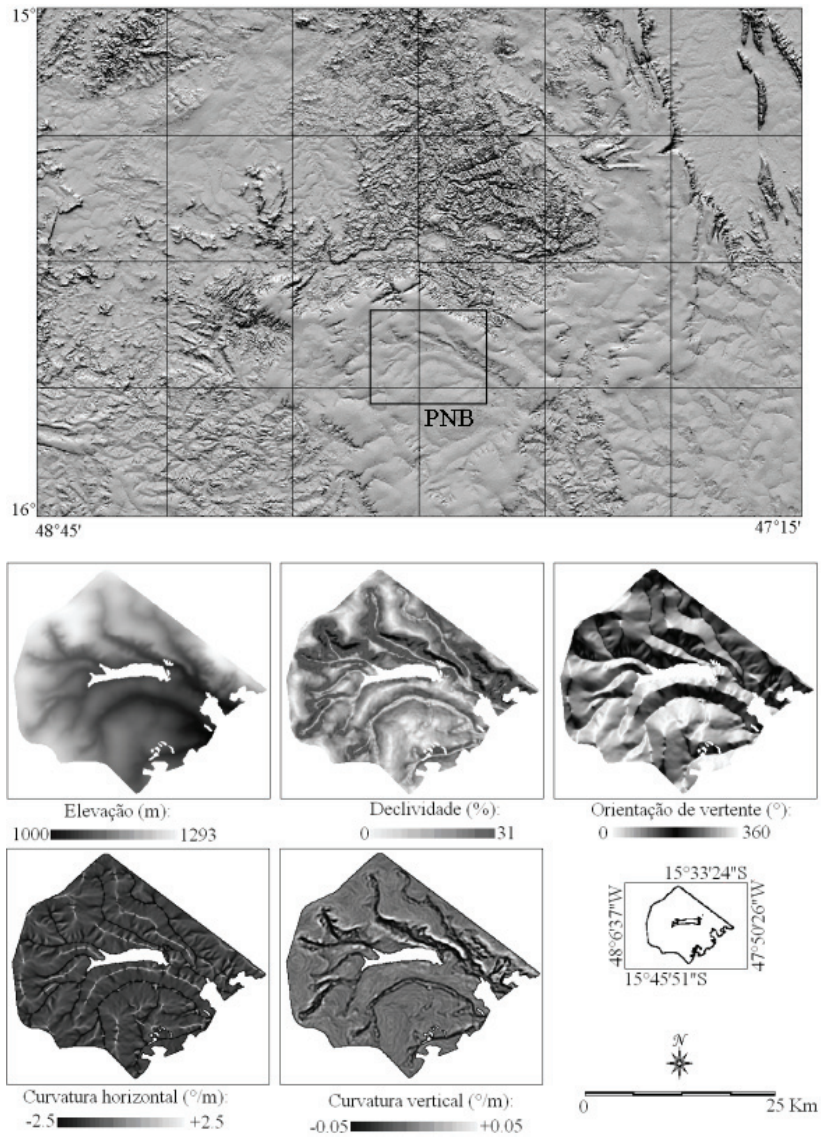

Figura 2. Relevo da área do entorno (acima) e mapas de variáveis morfométricas do Parque Nacional de Brasília.

àquele exibido pelos dados topográficos. Sobre um único interflúvio (como, por exemplo, na porção noroeste) podem ser encontrados diversos tipos de vegetação. Apesar disso, algumas variações morfométricas mostraram-se promissoras como indicação da distribuição espacial de algumas classes de vegetação.

A classe mata-galeria (A) mostra-se condicionada pela elevação, com distribuição associada a terrenos mais baixos. Os mapas sugerem também que a mata-galeria (A) está restrita a terrenos convergentes (curvatura horizontal negativa) e de menor declividade, uma vez que acompanham os canais de drenagem. O cerrado stricto sensu (B) mostrouse associado a terrenos mais planos e o campo limpo (E) parcialmente associado a faixas íngremes na vizinhança de áreas de mata-galeria.

A curvatura vertical mostrou-se uma variável organizada em regiões (manchas), num padrão definido por convexidades e concavidades distribuídas sobre diferentes segmentos de matrizes relativamente retilíneas. Além da mancha de campo limpo (E) ao longo da convexidade que corresponde à faixa íngreme descrita anteriormente no entorno da matagaleria, observou-se que todas as ocorrências de cerrado stricto sensu (B) estiveram associadas a regiões pouco mais côncavas a mais retilíneas do terreno, assim como o campo cerrado (C) e o campo sujo (D). Estas três últimas 
não apresentaram características da curvatura vertical que as diferenciassem entre si.

A única formação que se mostrou restrita a concavidades foi a mata-galeria (A), porém esta é uma associação aparente, ou indireta, pois está de fato associado a canais de drenagem. No caso particular do relevo desta área, a derivação do Modelo Digital de Elevação (MDE) evidenciou a drenagem como concavidade, porém pode haver áreas com outro padrão de curvatura vertical. Canais de drenagem são mais apropriadamente evidenciados pela curvatura horizontal, caracterizados como terrenos convergentes (curvatura negativa). Observase que a mata-galeria se distribui em manchas contínuas ao longo do curso dos principais rios, com maior freqüência nos trechos em que o canal tem baixa declividade.

A relação das classes de vegetação com a orientação de vertentes não se mostrou evidente pela comparação entre os mapas. Entretanto, pode-se esperar que classes de áreas diminutas e únicas tendem a se posicionar numa situação particular de orientação, assim como das demais variáveis, o que pode causar uma falsa sugestão de controle por estas variáveis. Nesta situação se encontra o campo limpo úmido (F), o brejo (G), a mata de interflúvio $(\mathrm{H})$, e o reflorestamento (I) e em menor grau o campo cerrado com Trembléias (J), campo limpo com Murundum (L) e campo sujo com presença de Lychnophora ericoides (amica) e "canela de ema" (M).
As observações advindas da apreciação preliminar dos mapas mostram que os tipos vegetacionais mapeados não estão associados de maneira unívoca a nenhuma das variáveis morfométricas isoladamente. A distribuição das freqüências para cada classe de vegetação e para o PNB (Fig. 3) revela que as preferências de cada tipo vegetacional a determinadas condições topográficas não configuram condições excludentes. Nota-se que mesmo a mata-galeria (A), associada a concavidades e convergências devido à topografia de canais de drenagem (Fig. 1-2), ocorre, embora em menor proporção, em terrenos de curvaturas positivas (divergentes e convexos). A mesma formação distribuição polimodal da elevação, em função das altitudes de ocorrência das áreas associadas à drenagem.

Observa-se que as formações com freqüências relativamente mais altas em áreas de maior declividade, mata-galeria (A) e campo limpo (E), distribuem-se numa faixa intermediária da amplitude altimétrica da área. As mesmas correspondem também às maiores dispersões de curvatura vertical, numa confirmação da relação entre declividades e as variações de curvatura. A formação cerrado stricto sensu (B) tem a mesma distribuição altimétrica, porém concentrada em áreas de pequena declividade e curvaturas. As declividades altas desta classe correspondem à transição entre os dois estratos altimétricos da grande mancha central que ocupa, expressa nas duas modas de sua distribuição.
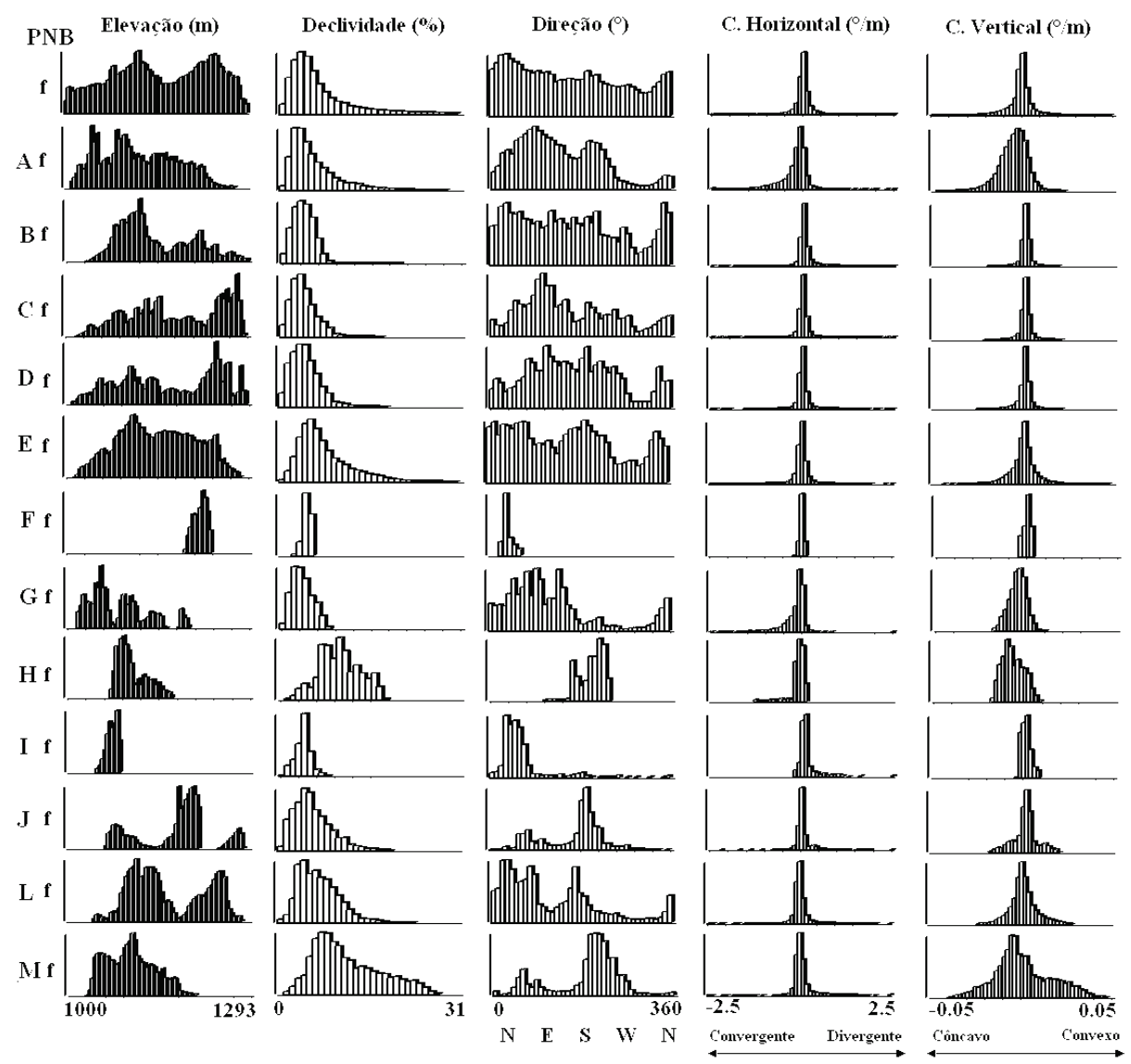

Figura 3. Distribuição (f) das variáveis topográficas nas classes de vegetação do Parque Nacional de Brasília. 
As formações campo cerrado (C) e o campo sujo (D) embora sejam expressivas no mapa de vegetação, não foram definidas nas variáveis de modo claro, bem como nos histogramas. As demais classes, campo limpo úmido (F), o brejo $(\mathrm{G})$, a mata de interflúvio $(\mathrm{H})$, e o reflorestamento (I) e em menor grau o campo cerrado com Trembléias (J), campo limpo com Murundum (L) e campo sujo com presença de Lychnophora ericoides (amica) e "canela de ema" (M) apresentam características extremamente particularizadas devido as suas respectivas ocorrências serem correspondentes à manchas diminutas e dispersas, podendo sugerir informações equivocadas a respeito de uma determinada ocorrência.

Embora a comparação de mapas mostrasse notáveis relações entre algumas classes e a curvatura vertical, principalmente, os histogramas das curvaturas indicam a dificuldade de aplicação analítica dessas variáveis na classificação da vegetação. A simetria da distribuição de ambas curvaturas (horizontal e vertical) é uma característica dessas variáveis, independente do tipo de relevo (Valeriano \& Carvalho Junior 2003). Ocasionalmente, podem ocorrer variações de dispersão, sobretudo da curvatura vertical, maior em terrenos mais movimentados, porém com distribuição sempre simétrica e centrada em torno do valor nulo. As formações mata-galeria (A) e campo limpo (E) apresentaram maior dispersão de curvatura vertical, coerentemente com a maior freqüência de declividades altas, sobretudo a última. As únicas assimetrias notáveis nas distribuições de curvaturas ocorreram sob mata-galeria, devido à sua associação com canais de drenagem, que corresponde a freqüências ligeiramente maiores para curvaturas negativas. Tal característica implica na predominância de terrenos convergentes (horizontalmente), que no caso local se mostraram correlatos a concavidades (verticalmente).

Dada a impossibilidade de se estabelecerem associações unívocas entre cada variável e a distribuição dos 13 tipos de vegetação mapeados, procurou-se desenvolver análises estatísticas multivariadas para tentar relacioná-la a combinações específicas de condições morfométricas. As análises estatísticas realizadas foram empregadas sobre o agrupamento de classes vegetacionais em função da semelhança estrutural de sua vegetação. Assim foram gerados novos mapas de vegetação referência.

A análise discriminante foi significativa na separação dos grupos vegetacionais com base nas variáveis morfométricas (Wilks' Lambda geral: 0,549 F $(20,216)=21,407 \mathrm{p}<0,000)$. As maiores significâncias na construção do modelo foram as variáveis orientação de vertente $(A)$, elevação $(h)$ e declividade (G) com Wilks' lambdas de 0,652, 0,645 e 0,604, respectivamente. Através da distância entre os centróides (Distância de Mahalanobis) dos grupos no espaço discriminante verificou-se que os grupos mais distantes entre si foram campo limpo e mata $(2,769)$ e as mais próximos foram campo cerrado e cerrado stricto sensu $(0,420)$. A proximidade destes últimos quanto ao conjunto de variáveis morfométricas que os definiram é comparável com a estrutura vegetacional, uma vez que ambas as feições vegetacionais são muito parecidas. O campo cerrado é a forma de vegetação intermediária entre o campo sujo e o cerrado stricto sensu, se diferenciando deste último apenas pelo maior espaçamento e a sua menor quantidade de vegetação arbórea comparativamente com o cerrado stricto sensu.

As análises discriminantes indicaram também que as variáveis topográficas podem variar em gradiente e não de forma discreta, o que levaria a vegetação ter faixas transicionais e não limites bem definidos. Além disso, as variáveis topográficas explicaram parte da variação vegetacional, no entanto, outros fatores podem ser importantes. Assim, nessa graduação de campo limpo a cerrado stricto sensu (campo limpo, campo sujo, campo cerrado e cerrado stricto sensu), o aumento de biomassa que acompanha o adensamento arbóreo se deve a um conjunto de três fatores: o pedológico, pela oligotrofia mineral, toxidez por alumínio e diferenças de drenagem e profundidade dos solos; o pirogênico, pela ação do fogo na biota; e o climático, principalmente pelo efeito sazonal que limita a disponibilidade de água (Coutinho 1990; 2000; Ribeiro \& Walter 1998).

Como o campo limpo e a mata apresentaram subfisionomias, foram feitas análises discriminantes separadas para as mesmas. O objetivo dessas análises foi verificar se as variáveis topográficas também seriam boas preditoras dessas subfisionomias. Para o campo limpo, a análise mostrou-se significativa na separação dos grupos vegetacionais com base nas variáveis morfométricas (Wilks' Lambda: 0,547 F $(10,360)=12,640 \mathrm{p}<0,000)$. As maiores significâncias na construção do modelo foram altitude $(0,713)$, orientação de vertente $(0,676)$, e curvatura vertical $(0,579)$.

A distância entre os centróides dos grupos no espaço discriminante (Distância de Mahalanobis) mostrou que os grupos mais distantes entre si foram campo limpo e campo limpo úmido $(4,279)$ e as mais próximos foram campo limpo e campo limpo com Murundum $(0,648)$, que possuem uma certa sobreposição entre si. Enquanto o campo limpo úmido se encontra com uma distribuição mais restrita e isolada dos outros dois. Isso pode se explicar por sua preferência por ambientes mais úmidos e áreas de encostas de vales. Nestes ambientes, geralmente o lençol freático permanece na superfície durante parte do ano e, no período de seca, sofre um rebaixamento, em que as camadas subsuperficiais mantêm o encharcamento do solo (Pivello et al. 1998). Enquanto que a sobreposição entre campo limpo e campo limpo com Murundum se deve ao fato deste ser basicamente um campo úmido em terreno pouco inclinado, com ilhas de campo limpo, arredondadas e um pouco mais altas. Os murunduns são formados por erosão diferencial do terreno e deposição da terra por térmitas, recobertas por vegetação de Cerrado e solo permanentemente saturado de água entre os murunduns (Araújo Neto 1986).

Para a mata, a análise discriminante mostrou-se significativa na separação dos grupos vegetacionais com base nas variáveis morfométricas, (Wilks' Lambda: 0,453 F 
$(8,334)=20,234 \mathrm{p}<0,000)$. As maiores significâncias na construção do modelo foram altitude $(0,713)$, orientação de vertente $(0,676)$, e curvatura vertical $(0,579)$.

Observando a distância entre os centróides dos grupos no espaço discriminante (distância de Mahalanobis) verificou-se que os grupos mais distantes entre si foram mata de interflúvio e mata-galeria $(5,176)$ e as mais próximas foram brejo e mata-galeria $(0,286)$. A distância entre o brejo e mata-galeria não foram significativas. Isto implica na grande sobreposição entre estes grupos. Enquanto a mata de interflúvio se encontra com uma distribuição mais restrita e isolada dos outros dois.

Estes resultados reafirmam que a posição do relevo é um dos determinantes da composição florística e de estrutura das comunidades de interflúvio (Fonseca \& Silva Junior 2004), uma vez que estas se localizam em locais mais altos. Enquanto que a sobreposição entre mata-galeria e brejo se deve ao fato deste último tipo de vegetação ocupar planícies permanentemente encharcadas que freqüentemente surgem nas bordas nas matas-galeria ou mesmo matas ciliares dos vales rasos da região de Cerrado (Ribeiro \& Walter 1998). A característica marcante desse tipo de ambiente é o nível da água sempre acima do solo, embora haja variações durante o ano. Tal condição do terreno só ocorre sob baixas declividades, em situação de vale de fundo plano.

Quanto aos processamentos baseados nas análises discriminantes, a geração da imagem da primeira função discriminante da área permitiu a obtenção de classificações comparáveis ao mapa referência. No Parque Nacional de Brasília só foi possível verificar algumas tendências, e o produto obtido não foi satisfatório, como já era esperado, uma vez que se trata de uma área de relevo homogêneo de feições bastante discretas (Fig. 4). Por outro lado, as suas subfisionomias apresentaram bons resultados, comparáveis às suas posições no mapa de vegetação de referência. No campo limpo (Fig. 5), exceto pela classe campo limpo úmido que foi superestimado no mapa gerado, as demais classes mostraram-se bem semelhantes ao mapa referência, tanto por sua extensão quanto pelo seu posicionamento. Na mata (Fig. 6) o produto obtido foi quase idêntico ao mapa de referência, especialmente pela classe mata de interflúvio. Estes resultados indicam que para este tipo de vegetação, Cerrado, os processamentos não se aplicam ao mapeamento da vegetação ao nível de fitofisionomias, podendo, porém, ser aplicável as suas subfisionomias.
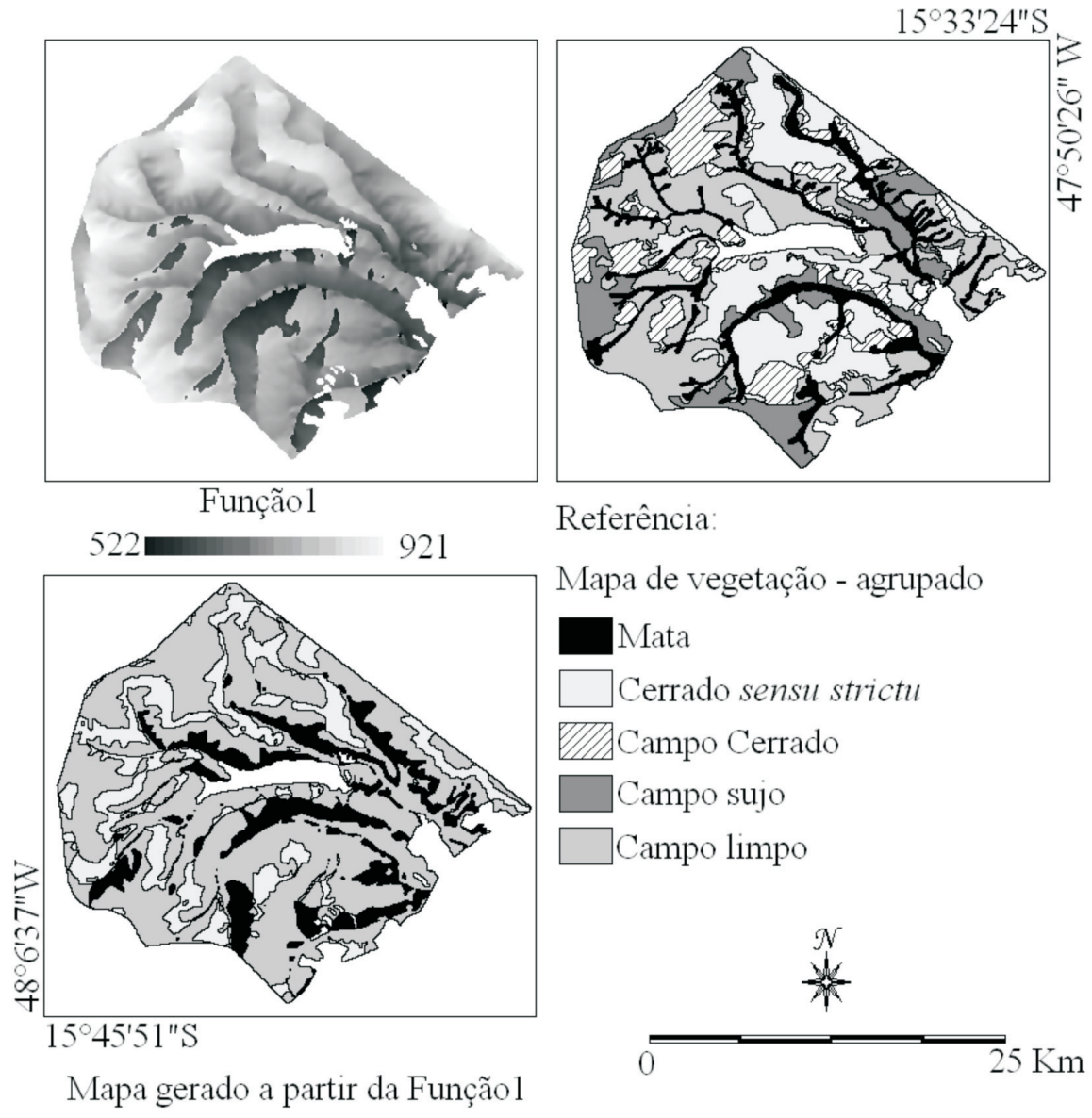

Referência

Mapa de vegetação - agrupado

Mata

Cerrado sensu strictu

UAC Campo Cerrado

Campo sujo

Campo limpo

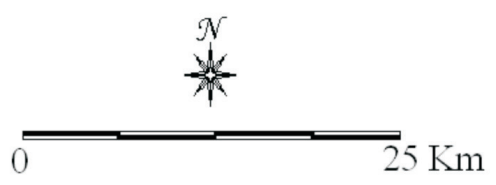

Figura 4. Imagem da função discriminante 1, classificação por fatiamento da função discriminante 1 sobre variáveis morfométricas para o Parque Nacional de Brasília e mapa de vegetação referência. 


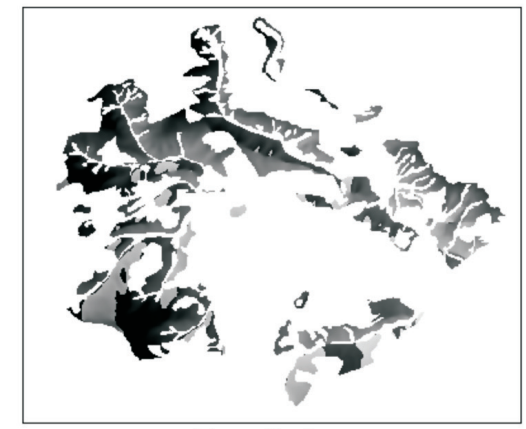

Funçãol

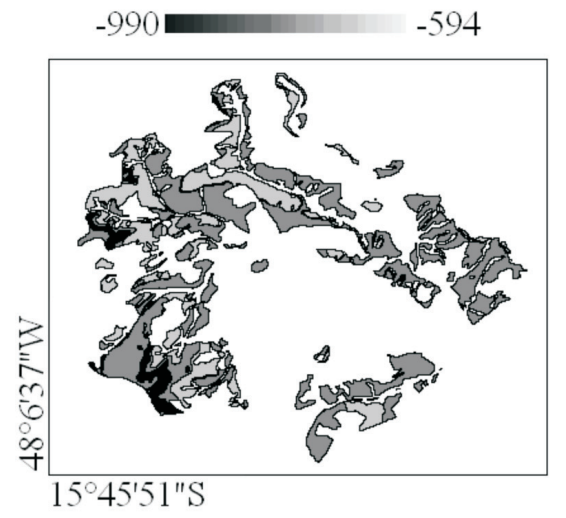

Mapa gerado a partir da Função 1

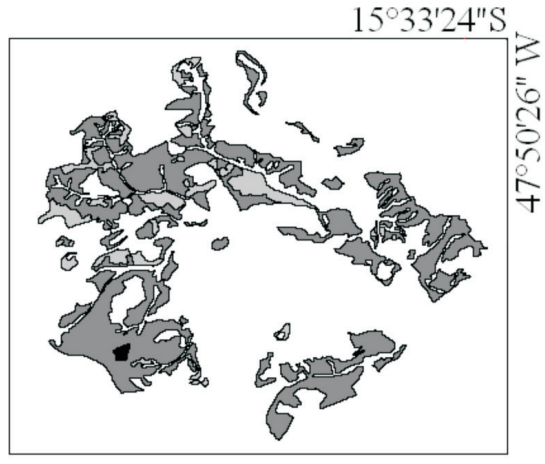

Referência:

Mapa de vegetação - Campo limpo

$\square$ Campo limpo

Campo limpo úmido

Campo limpo com murundum

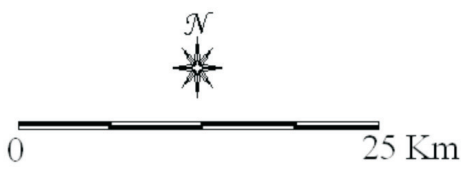

Figura 5. Imagem da função discriminante 1, classificação por fatiamento da função discriminante 1 sobre variáveis morfométricas para o campo limpo do Parque Nacional de Brasília e mapa de vegetação referência.

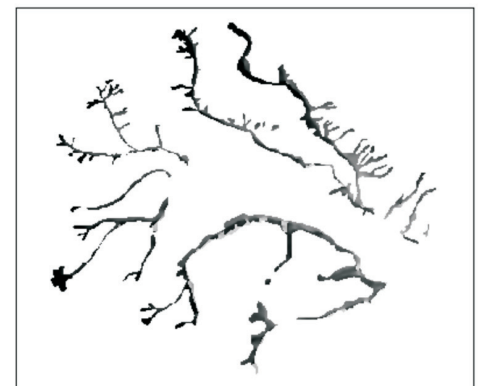

Funçãol

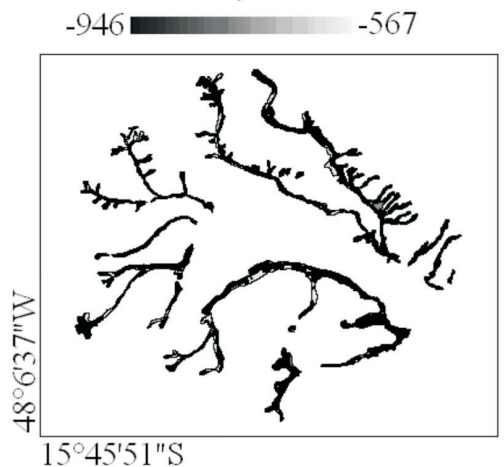

Mapa gerado a partir da Funçãol

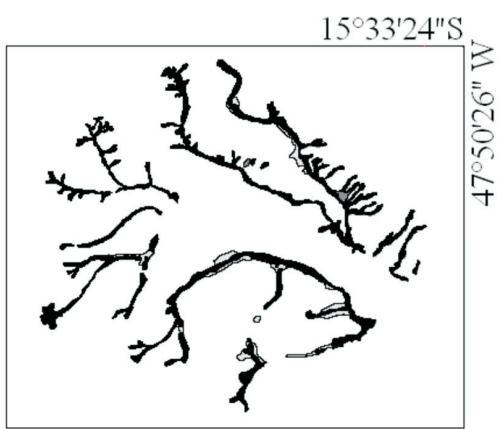

Referência

Mapa de vegetação - Mata

Mata galeria

Brejo

Mata de Interflúvio

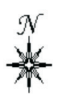

$25 \mathrm{Km}$

Figura 6. Imagem da função discriminante 1, classificação por fatiamento da função discriminante 1 sobre variáveis morfométricas para a mata do Parque Nacional de Brasília e mapa de vegetação referência. 


\section{Conclusões}

O trabalho foi conduzido com o intuito de avaliar as variáveis morfométricas extraídas de modelos digitais de elevação do SRTM para subsidiar o mapeamento da vegetação na área do Parque Nacional de Brasília. A partir dos resultados obtidos, foram assinaladas as seguintes conclusões:

- O mapeamento da vegetação na escala 1:10.000 mostrou grande detalhamento espacial e temático em relação à distribuição espacial dos dados morfométricas, com a ocorrência de muitas classes ao longo de uma mesma feição topográfica; - Muitas classes discriminadas no mapa de referência são funcionalmente semelhantes, distintas por características florísticas não condicionadas pelo relevo;

- Orelevo do Parque é relativamente uniforme em relação a outros tipos de terreno em seu entorno, o que, aliado às características do mapa de vegetação, não permite dizer que as limitações encontradas neste estudo possam ser estendidas a todo o bioma Cerrado; - Embora tivesse havido correspondência entre determinados padrões topográficos e a distribuição espacial de algumas classes de vegetação, não foi possível associá-las a limites rígidos de amplitude de cada variável morfométrica isolada, no nível categórico em que foram mapeadas;

- Análises multivariadas permitiram o mapeamento experimental até o nível de subfisionomias, através de variáveis agrupadas sob funções discriminantes, que indicaram campo limpo e mata como os grupos morfometricamente mais distintos; - Dentre as fisionomias, as análises permitiram a separação entre mata-galeria e mata de interflúvio e, de modo menos pronunciado, entre campo limpo e campo limpo úmido.

\section{Agradecimentos}

Polyanna da Conceição Bispo agradece ao CNPq pela bolsa de mestrado concedida durante o desenvolvimento do trabalho e à CAPES pela atual bolsa de doutorado.

\section{Referências bibliográficas}

Araújo Neto, M.D.; Furley, P.A.; Haridansan, M. \& Johnson, C.E. 1986. The murundus of the Cerrado region of Central Brazil. Journal of Tropical Ecology 2: 17-35.

Cardoso, E \& Schiavini, I. 2002. Relação entre distribuição de espécies arbóreas e topografia em um gradiente florestal na Estação Ecológica do Panga (Uberlândia, MG). Revista Brasileira de Botânica 25: 277-289.

Carvalho, D.A.; Oliveira Filho, A.T.; Vilela, E.A.; Curi, N.; Berg, E.V.D.; Fontes, M.A.L. \& Botezelli, L. 2005. Distribuição de espécies arbóreoarbustivas ao longo de um gradiente de solo e topografia em um trecho de floresta ripária do Rio São Francisco em Três Marias, MG, Brasil. Revista Brasileira de Botânica 28: 329-345.

Castro, A.A.J.F.; Martins, F.R.; Iamashiro, J.Y. \& Shepherd, G.J. 1999. How rich is the flora of Brazilian Cerrados? Annals of Missouri Botanical Garden 86: 192-221.

Coutinho, L.M. 1978. O conceito de cerrado. Revista Brasileira de Botânica 1: 17-23.

Coutinho, L.M. 1990. Fire in the ecology of Brazilian cerrado. In: Fire in the tropical biota. Ed. J.G. Goldammer. New York: Springer-Verlag. p. 82-105.

Coutinho, L.M. 2000. Cerrado. Disponível em <http:// eco.ib.usp.br/ cerrado $>$. Acesso em: out. 2006.

Dargie, T.C.D. 1984. On the integrated interpretation of indirect site ordinations: A case study using semi-arid vegetation in Southeastern Spain. Plant Ecology 55: 37-55.
Dargie, T.C.D. 1987. An ordination analysis of vegetation patterns on topoclimate gradients in South-East Spain. Journal of Biogeography 14: 197-211.

Ferreira, M.E. 2003. Análise do Modelo linear de mistura espectral na discriminação de fitofisionomias do Parque Nacional de Brasília (bioma Cerrado). Dissertação de Mestrado em Geociências Universidade de Brasília, Instituto de Geociências, Brasília.

Florinsky, I.V. \& Kuryakova, G.A. 1996. Influence of topography on some vegetation cover properties. Catena 27: 123-141.

Fonseca, M.S. \& Silva Júnior, M.C. 2004. Fitossociologia e similaridade florística entre trechos de Cerrado sentido restrito em interflúvio e em vale no Jardim Botânico de Brasília, DF. Acta Botanica Brasilica 18: 19-29.

Furley, P.A. 1996. The influence of slope on the nature and distribuition of soils and plant communities in the Central Brazilian Cerrado. Advances in Hillslope Processes 1: 327-345.

Furley, P.A. \& Ratter, J.A. 1988. Soil resources and plant communities of the Central Brazilian Cerrado and their development. Journal of Biogeography 15: 97-108.

Kellndorfer, J.; Walker, W.; Pierce, L.; Dobson, C.; Fites, J.A.; Hunsaker, C.; Vona, J. \& CLutter, M. 2004. Vegetation height estimation from Shuttle Radar Topography Mission and National Elevation Datasets. Remote Sensing of Environment 93: 339-358.

Kirkby, M.; Atkinson, K. \& Lockwood, J.G. 1990. Aspect vegetation cover and erosion on semi-arid hillslopes. In: Thomes, J. (Ed.). Vegetation and geomorphology. New York: John Wiley. p. 25-39.

Manly B. F. J. Multivariate Satistical Metods A primer 2a. ed.. New Zealand, Chapman \&Hall, p.210.1994.

Oliveira Filho, A.T. \& Martins, F.R. 1986. Distribuição, caracterização e composição florística das formações vegetais da região da Salgadeira, na Chapada dos Guimarães, MT. Revista Brasileira de Botânica 9: 207-223.

Oliveira Filho, A.T.; Shepherd, G.J.; Martins, F.R. \& Stubbleline, W.H. 1989. Environmental factors effecting physiognomic and floristic variation in área of Cerrado in Central Brazil. Journal of Tropical Ecology 5: 413-431.

Oliveira Filho, A.T.; Curi, N.; Vilela, E.A. \& Carvalho, D.A. 1997. Tree species distribuition along soil catenas in a riverside semideciduous forest in the southeastern Brazil. Flora 192: 47-64.

Pivello, V.R., Barbieri, R.F., Ruggiero, P.G.C. \& Oliveira Filho, F. 1998. Análise da variação fisionômica na ARIE Cerrado Pé-de-Gigante (Santa Rita do Passa Quatro-SP) em relação às características pedológicas locais. Pp. 7-29. In: IV Simpósio de Ecossistemas Brasileiros. v.3. São Paulo, ACIESP.

Ramos, P.C.M. 1995. Vegetation communities and soils in National Park of Brasilia. Tese de Doutorado em Biologia, University of Edinburgh, Edinburgh.

Ribeiro, J.F. \& Walter, T.M.B. Fitofisionomias do bioma Cerrado. Pp.89166.In: Sano,S.M.; Almeida, S.P. (Ed). Cerrado:ambiente e flora. Planaltina, Embrapa Cerrados.

Ruggiero, P.G.C.; Pivello, V.R.; Sparovek, G.; Teramoto, E. \& Pires Neto, A.G. 2006. Relação entre solo, vegetação e topografia em área de cerrado (Parque Estadual de Vassununga, SP): como se expressa em mapeamentos? Acta Botanica Brasilica 20: 383-394.

Schmidt, J.; Evans, I.S. \& Brinkmann, J. 2003. Comparison of polynomial models for land surface curvature calculation. International Journal of Geographical Information Science 17: 797-814.

Valeriano, M.M. 2003. Curvatura vertical de vertentes em microbacias pela análise de modelos digitais de elevação. Revista Brasileira de Engenharia Agrícola e Ambiental 7: 539-546.

Valeriano, M.M \& Carvalho Júnior, O.A. 2003. Geoprocessamento de modelos digitais de elevação para mapeamento da curvatura horizontal em microbacias. Revista Brasileira de Geomorfologia 4: 17-29.

Valeriano, M.M. Modelo digital de variáveis geomorfométricas com dados SRTM para o território nacional: o projeto TOPODATA. 2005. In: Simpósio Brasileiro de Sensoriamento Remoto XII, Goiânia. Anais... São José dos Campos: INPE, 2005. p. 3595-3602.

Valeriano, M.M; Kuplich, T.M.; Storino, M.; Amaral, B.D.; Mendes, J.N. \& Lima, D.J. 2006. Modeling small watersheds in Brazilian Amazônia with Shuttle Radar Topographic Mission - 90m data. Computers e Geosciences 32: 1169-1181.

Velázquez-Rosas, N.; Meave, J. \& Vázquez-Santana, S. 2002. Elevation variation of leaf traits in montane rain forest tree species at La Chinantla, Sourthen Mexico. Biotropica 34: 534-546.

Versão eletrônica do artigo em www.scielo.br/abb e http://www.botanica.org.br/acta/ojs 